Check for updates

Cite this: RSC Adv., 2018, 8, 17346

Received 18th February 2018 Accepted 23rd April 2018

DOI: $10.1039 / c 8 r a 01504 j$

rsc.li/rsc-advances

\section{Modeling, optimization and experimental studies of supported nano-bimetallic catalyst for simultaneous total conversion of toluene and cyclohexane in air using a hybrid intelligent algorithm}

\begin{abstract}
Mohammad Zabihi (D) * and Nasser Babajani
This study reveals the simultaneous deep oxidation of toluene and cyclohexane over optimal supported bimetallic catalysts over almond shell based activated carbon. To the best of our knowledge, this study is the first to construct a hybrid intelligent model to predict and determine an optimal supported bimetallic catalyst to oxidize aromatic and aliphatic compounds in air. The effects of preparation and operating parameters, including oxidation temperature, initial concentration of VOCs, structure of the catalyst and metal oxide content, on VOCs conversion were studied by modeling a database containing 50 data points derived from our previously published study, by an artificial neural network (ANN). Reported experimental data were predicted by a feed-forward network with 11 neurons and tansig function in the hidden layer. The non-linear network demonstrated stronger influence of oxidation temperature and cobalt content on the complete conversion of toluene and cyclohexane in the mixture. A hybrid model containing a genetic algorithm (GA) and an ANN were employed to realize the optimum catalyst at constant operating conditions for the complete conversion of toluene and cyclohexane in air. A well dispersed optimal alloy catalyst with $8 \mathrm{wt} \%$ metal oxide content $(2.5 \mathrm{wt} \%$ copper oxide and $5.5 \mathrm{wt} \%$ cobalt oxide) over activated carbon was synthesized by heterogeneous deposition-precipitation for the complete conversion of toluene (model $=95.50 \%$, experimental $=96 \%$ ) and cyclohexane (model = $91.88 \%$ and experimental $=91 \%$ ), simultaneously. Characterizations of the optimal catalyst were carried out by XRD, TEM, ICP, FESEM and BET analyses to justify its highest performance.
\end{abstract}

\section{Introduction}

Volatile organic compounds (VOCs) in effluents are highly mortal to human beings and animals. ${ }^{\mathbf{1 , 2}}$ Therefore, they must be removed from air before they are released in the environment., ${ }^{3,4}$ An efficient method of VOCs removal from air is the catalytic oxidation by appropriate supported catalysts. ${ }^{5,6}$ Bimetallic catalysts supported on activated carbons are becoming more popular for the total oxidation of aromatic and aliphatic volatile compounds in air. ${ }^{7,8}$ Porous activated carbon has been extensively applied as a support for the active sites in the preparation of bimetallic catalysts. ${ }^{9}$ The complete oxidation of aromatic and aliphatic compounds, such as toluene and cyclohexane are highly affected by the preparation and operating parameters, including the metal content over the support, catalyst morphology (alloy and coreshell), oxidation temperature and the VOCs concentration in the feed. Recently, few studies reported the preparation of supported bimetallic catalysts for the removal of VOCs from air. Although

Chemical Engineering Faculty, Sahand University of Technology, P. O. Box 51335-1996, Sahand New Town, Tabriz, Iran. E-mail: zabihi@sut.ac.ir numerous scientific studies have published the use of bimetallic catalysts for the total oxidation of VOCs in a mixture, only a few studies have reported the simultaneous oxidation of aliphatic and aromatic compounds.

Modeling of catalytic oxidation consists of theoretical and numerical methods, which rely on fundamental and governing equations of the process, but not on the knowledge of process principles. ${ }^{10,11}$ Artificial neural networks (ANN) are important examples of numerical modeling that can accurately predict the experimental data. ${ }^{\mathbf{1 2 - 1 4}}$ Among various networks, the feed-forward network is extensively used for the determination of suitable relationships between input variables and output data. ${ }^{\mathbf{1 5 , 1 6}}$ Available literature indicates that the few attempts have been made to model the oxidation of VOCs in a multi-component feed using supported catalysts. The presence of an aliphatic compound and its oxidation products may affect the toluene conversion due to the competition for the active sites. Therefore, novel hybrid numerical methods were utilized for the prediction and detection of optimal conditions due to the complex nature of catalytic oxidation mechanism and kinetics. ${ }^{17,18}$ Rashidi et al. ${ }^{19}$ proposed the hybrid computational ANN-Genetic Algorithm (GA) modelling 
of toluene oxidation over perovskite-type nanocatalysts. They found that the optimum values of toluene oxidation obtained via prediction model was $92.7 \%$ at constant temperature. Appropriate $\mathrm{Ce}$ and $\mathrm{Cu}$ contents in the structure of the nanocatalysts were calculated by a designed network with acceptable accuracy in comparison to experimental data. Izadkhah et al. ${ }^{\mathbf{2 0}}$ investigated the hybrid ANN-GA method to find an optimal nanocatalyst for the removal of ethyl acetate from air. Fe-Ag-ZSM-5, V-Ag-ZSM-5 and Ni-Ag-ZSM-5 catalysts were obtained as optimum catalysts with higher activity than Ag-ZSM-5. Oskoui et al. ${ }^{21}$ studied the catalytic activity of perovskite nano-catalysts for the conversion of toluene in air. Artificial neural network was applied for the modelling and optimization of preparation conditions of the sol-gel method. Bahrami et al. ${ }^{12}$ determined the optimal performance of $\mathrm{CeO}_{2}$ $\mathrm{MO}_{x}(\mathrm{M}=\mathrm{Mn}, \mathrm{Fe}$ and $\mathrm{Cu})$ for the reduction of NO and CO by the hybrid ANN-GA method. The results indicated that the maximum conversions of NO and CO were measured $80 \%$ and $72 \%$, respectively, by using a bimetallic $\mathrm{Ce}-\mathrm{Cu}$ sample, while the optimum value of calcination temperature was chosen to be $500{ }^{\circ} \mathrm{C}$.

The scope of this study was to realize optimal bimetallic catalysts supported on almond shell-activated carbon for the total oxidation of toluene and cyclohexane in air. Intelligent hybrid machine learning (ANN-GA) was applied to show the VOCs' oxidation behavior in a fixed bed micro-reactor at various operating conditions by using our published data. ${ }^{9}$ Therefore, the experimental data were modeled mathematically by a neural network, while the reaction temperature, cyclohexane and toluene concentrations in the feed, cobalt and copper content and the structure of the catalyst (core-shell and alloy) were selected as input variables, and the conversion of toluene and cyclohexane were the outputs of the network. Optimization of preparation variables at constant operating conditions was another objective of this study. Finally, the optimum sample with the best performance was prepared based on the suggested preparation conditions obtained from the hybrid model.

\section{Methods and materials}

\subsection{Materials and catalytic oxidation}

Bimetallic catalysts (alloy and two core-shell samples) supported onto the almond shell based activated carbon were synthesized by heterogeneous deposition-precipitation (HDP) methods. Initially, the as-prepared activated carbon derived by physical activation at $800{ }^{\circ} \mathrm{C}$ was added to the nitrate solutions of copper and cobalt to construct the sample with $8 \mathrm{wt} \%$ metal content with different ratios (copper/cobalt: $1: 1,1: 3$ and $3: 1$ ). Three different catalysts were synthesized for the total oxidation of toluene and cyclohexane in air according to sequential and simultaneous HDP and were named s-HDP and co-HDP, respectively. Alloy supported bimetallic catalysts were prepared by simultaneously dispersing metal oxides, including those of cobalt and copper over the carbonaceous support via the HDP method (co-HDP). Calcination of the catalyst was conducted under nitrogen flow at $500{ }^{\circ} \mathrm{C}$ after filtration and drying the sample at $100{ }^{\circ} \mathrm{C}$ in an oven overnight.

Furthermore, one of the metal ions (cobalt or copper) was dispersed on the activated carbon by heterogeneous deposition-precipitation. The obtained material was filtered, dried and calcined under nitrogen flow. Then, the other metal ion (cobalt or copper ion) was deposited over the prepared sample (metal oxide/activated carbon) as a support by the HDP method to synthesize core-shell catalysts (s-HDP).

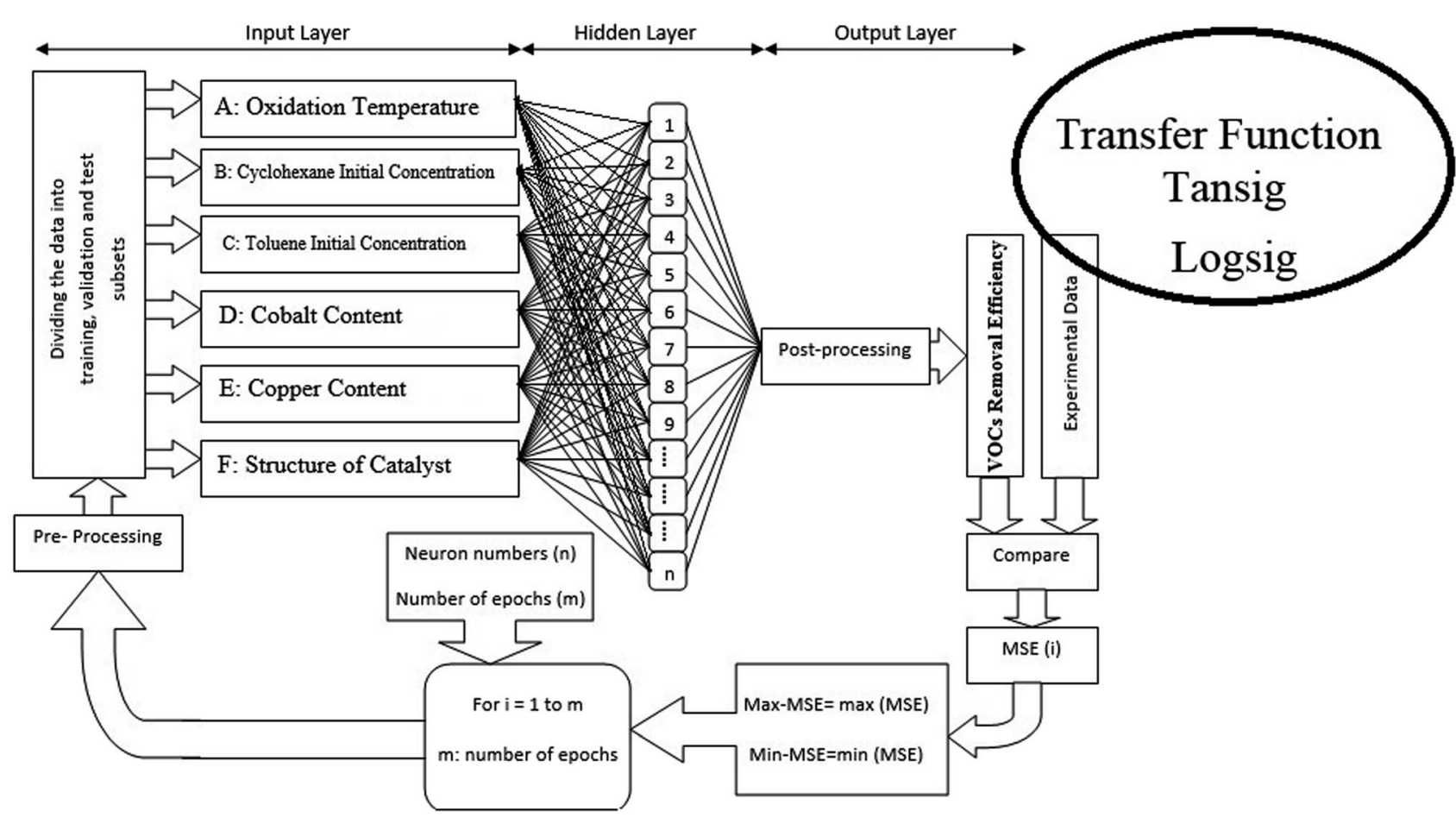

Fig. 1 ANN structure and related flowchart used in this study. 
Catalytic reaction tests were performed in the experimental set up for bi-component oxidation, as described in the previous paper. ${ }^{9}$ Catalytic oxidation was carried out in a tubular fixed bed reactor with the desired inlet concentration of toluene and cyclohexane (1000, 2000, 4000 and 8000 ppmv) at various reaction temperatures at a constant flow-rate and ambient pressure. Temperature of the reactor was adjusted to the desired level from 150 to $350{ }^{\circ} \mathrm{C}$. Gas chromatography-mass spectrometry (GC-MS) (Agilent) system equipped with a 5975C mass detector and a 30 m long HP-5MS stainless steel column was used to detect the products of the complete oxidation of VOCs. The results indicated that there were no intermediate products, such as carbon oxide, hydrogen, toluene and cyclohexane. The results obtained from the simultaneous complete oxidation of toluene and cyclohexane were recorded as the database for the hybrid artificial neural network and genetic algorithm. Toluene and cyclohexane removal efficiency (conversion) was calculated by the given equation:

$$
\operatorname{Re}_{\mathrm{VOC}}=\frac{C_{0}-C_{\mathrm{e}}}{C_{0}} \times 100
$$

where $C_{\mathrm{i}}$ and $C_{\mathrm{e}}$ are the VOCs concentrations at the reactor inlet and exit, respectively, and Re is the removal efficiency (deep conversion) of VOCs.

\subsection{Catalyst characterization}

Nitrogen adsorption/desorption was performed to measure the surface area and pore size at $77 \mathrm{~K}$ using a BEL (Japan) physicaladsorption apparatus. Specific surface area and average pore sizes were measured by Brunauer-Emmett-Teller (BET), and Barrett-Joyner-Halenda (BJH) methods, respectively. The X-ray diffraction (XRD) patterns of the resultant optimum bimetallic catalyst were recorded by employing a model D-64295 equipment acquired from STOE Company. XRD analysis was carried out at $30 \mathrm{kV}$ and $20 \mathrm{~mA}$ using copper $\mathrm{K} \alpha$ radiation at a scanning rate of $3^{\circ} \mathrm{min}^{-1}$. Morphology and particle size distribution of the as-prepared samples were characterized by recording transmission electron microscopy (TEM) micro-images using a EM208-Philips instrument equipped with a Schottky field emission gun operated at $100 \mathrm{keV}$ in the magnification range of $180000 \times$. The as-synthesized sample was characterized using a field-emission scanning electron microscope (FESEM) to determine its morphology and particle sizes at $15 \mathrm{kV}$ and vacuum conditions by a model S-4160 Hitachi equipment from Japan. Inductively coupled plasma (ICP) (PerkinElmer ${ }^{\circledR}$ Optima $^{\mathrm{TM}} 8000$ ICP-OES instrument) analysis was performed to determine the exact content of the active sites.

\subsection{Hybrid artificial neural network and genetic algorithm}

Multi-layer back-propagation neural network was applied herein due to its high capability in simulating and predicting catalytic reaction data. As shown in Fig. 1, a three layer back-propagation network with tangent sigmoid (tansig) and log-sigmoid (logsig) transfer functions at a hidden layer and a linear transfer function (purelin) at output were used for modelling the total oxidation of toluene and cyclohexane in air. Input variables in this network consisted of oxidation temperature (A), initial concentration of volatile organic compounds in the mixture solution (cyclohexane (B) and toluene (C)), amount of cobalt (D) and copper (E) over activated carbon as the active sites, and the structure of the catalysts (F) (alloy or core-shell). Input data were multiplied by specific weights and added to threshold values; then, the calculated results were used as feeds for each neuron in the hidden layer. Different training functions, including trainrp (Resilient back-propagation), traincgf (Fletcher-Reeves conjugate gradient back-propagation), traincgp (Polak-Ribière conjugate gradient back-propagation), traincgb (Powell-Beale conjugate gradient back-propagation), trainlm (Levenberg-Marquardt backpropagation), trainscg (Scaled conjugate gradient backpropagation), trainbfg (BFGS quasi-Newton back-propagation) and trainoss (One step secant back-propagation) were investigated to update the optimum weights and thresholds of the designed network. All training algorithms were evaluated by different neuron numbers from 1 to 20 to find the best size of the back-propagation network. Therefore, minimum MSE (Mean Square Error) (eqn (2)) values and $R^{2}$ correlation coefficient (eqn.(3)) values from the calculation of 100 epochs for each training algorithm were obtained by MATLAB (2017a) software. ${ }^{19}$

$$
\mathrm{MSE}=\frac{1}{N} \sum_{i=1}^{N}\left(y_{i, \mathrm{ANN}}-y_{i, \exp }\right)^{2}
$$

$$
R^{2}=\frac{\sum_{i=1}^{N}\left(y_{i, \exp }-\bar{y}\right)^{2}-\sum_{i=1}^{N}\left(y_{i, \exp }-y_{i, \mathrm{ANN}}\right)^{2}}{\sum_{i=1}^{N}\left(y_{i, \exp }-\bar{y}\right)^{2}}
$$

here, $y_{\exp }$ and $y_{\mathrm{ANN}}$ are the experimental and modeling outputs, respectively.

Genetic algorithm (GA) as a nonlinear optimization methodology was conducted for the realization of the optimal supported catalyst from the appropriate designed neural network, which could find the global extremum in a wide search space. GA toolbox in MATLAB (2017a) software was employed with defined parameters summarized in Table 1 . In the present proposal, the aim of the optimizer was to determine the optimal preparation parameters used as neural network feeds to simultaneously maximize the complete conversion of toluene and cyclohexane at

Table 1 Parameters and constraints of the genetic algorithm

\begin{tabular}{ll}
\hline GA parameters & Constraints of the problem \\
\hline Generation size $=1000$ & $\begin{array}{l}\text { Oxidation temperature }=250{ }^{\circ} \mathrm{C} \\
\text { (constant) } \\
\text { VOCs concentration }=1000 \mathrm{ppmv} \\
\text { (constant) }\end{array}$ \\
$\begin{array}{l}\text { Catalyst structure must } \\
\text { be an integer number }(1,2 \text { or } 3)\end{array}$ \\
$\begin{array}{l}2<\text { cobalt content }(\mathrm{wt} \%)<6 \\
\text { Elite count }\end{array}$ \\
$\begin{array}{l}\text { Crossover } \\
\text { fraction }=0.9 \text { and } \\
\text { doublepoint }\end{array}$ \\
$\begin{array}{l}\text { Mutation rate }=0.65 \\
\text { Objective functions }=\text { maximize (toluene and cyclohexane conversion) }\end{array}$
\end{tabular}




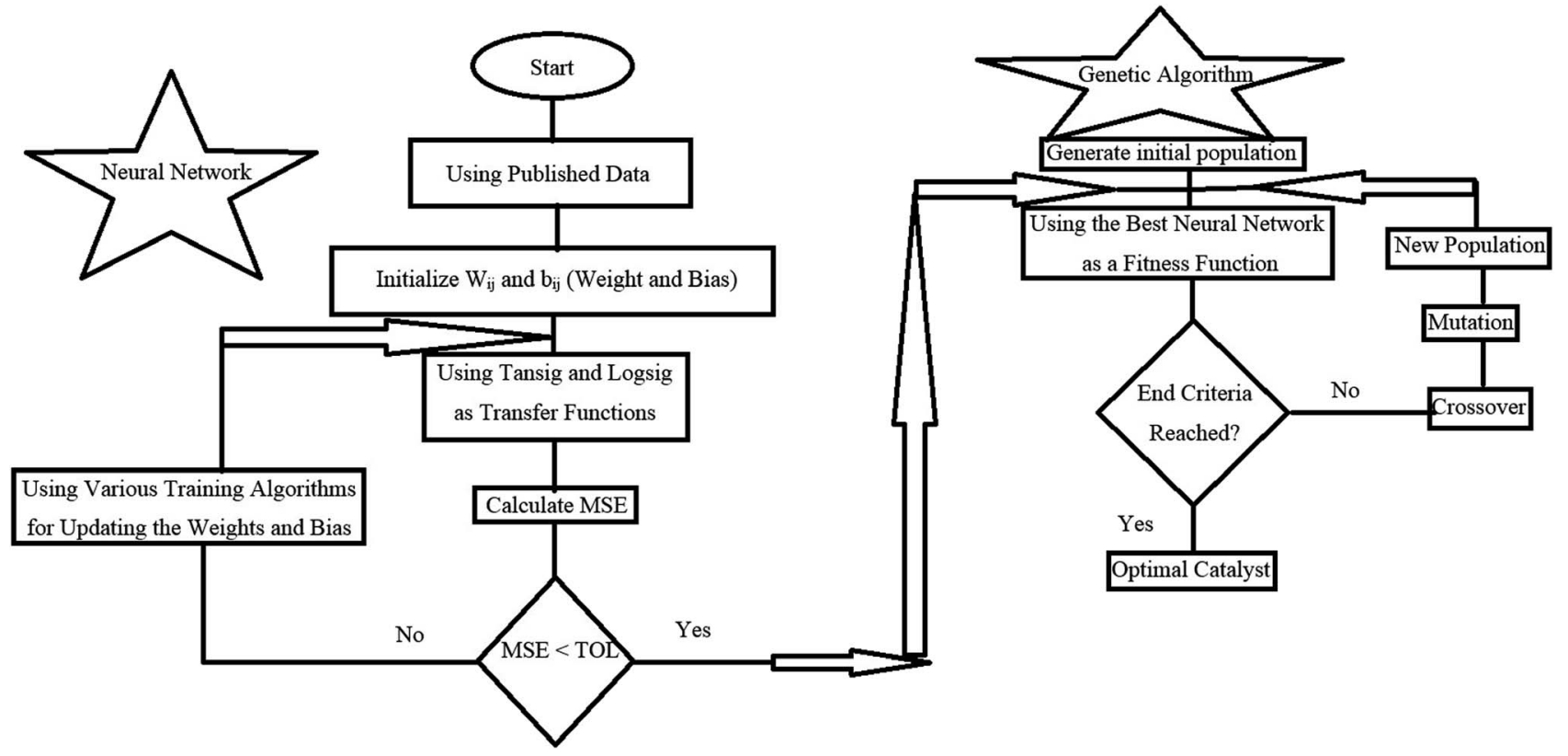

Fig. 2 Hybrid (ANN-GA) algorithm for the optimization of the supported bimetallic catalyst.

constant operating conditions. Therefore, two objective functions with six variables and specified constraints listed in Table 1 were used in the hybrid ANN-GA algorithm (Fig. 2). Virtual metal oxide contents and morphology were assumed by the GA algorithm as a feed to the ANN model. Subsequently, the catalytic performance of this formed sample was evaluated by the ANN model. Copper and cobalt loadings and the structure of the catalyst played the role of genes in every chromosome. Mutation and crossover were

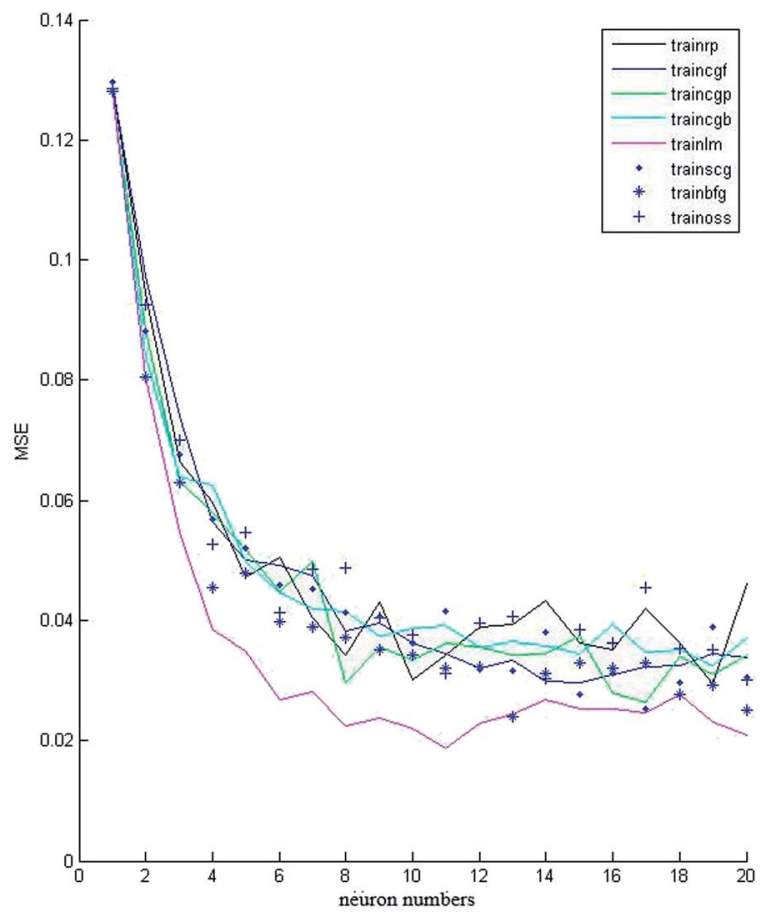

applied to reach the maximum conversion of VOCs in polluted air.

\section{Results and discussion}

\subsection{Modelling and validation}

In this study, 50 data points were applied from our previously published paper $^{7}$ to design the proposed neural network that

Fig. 3 Effect of the number of neurons on MSE and correlation coefficient $\left(R^{2}\right)$ values for various training algorithms (tansig function in the hidden layer). 

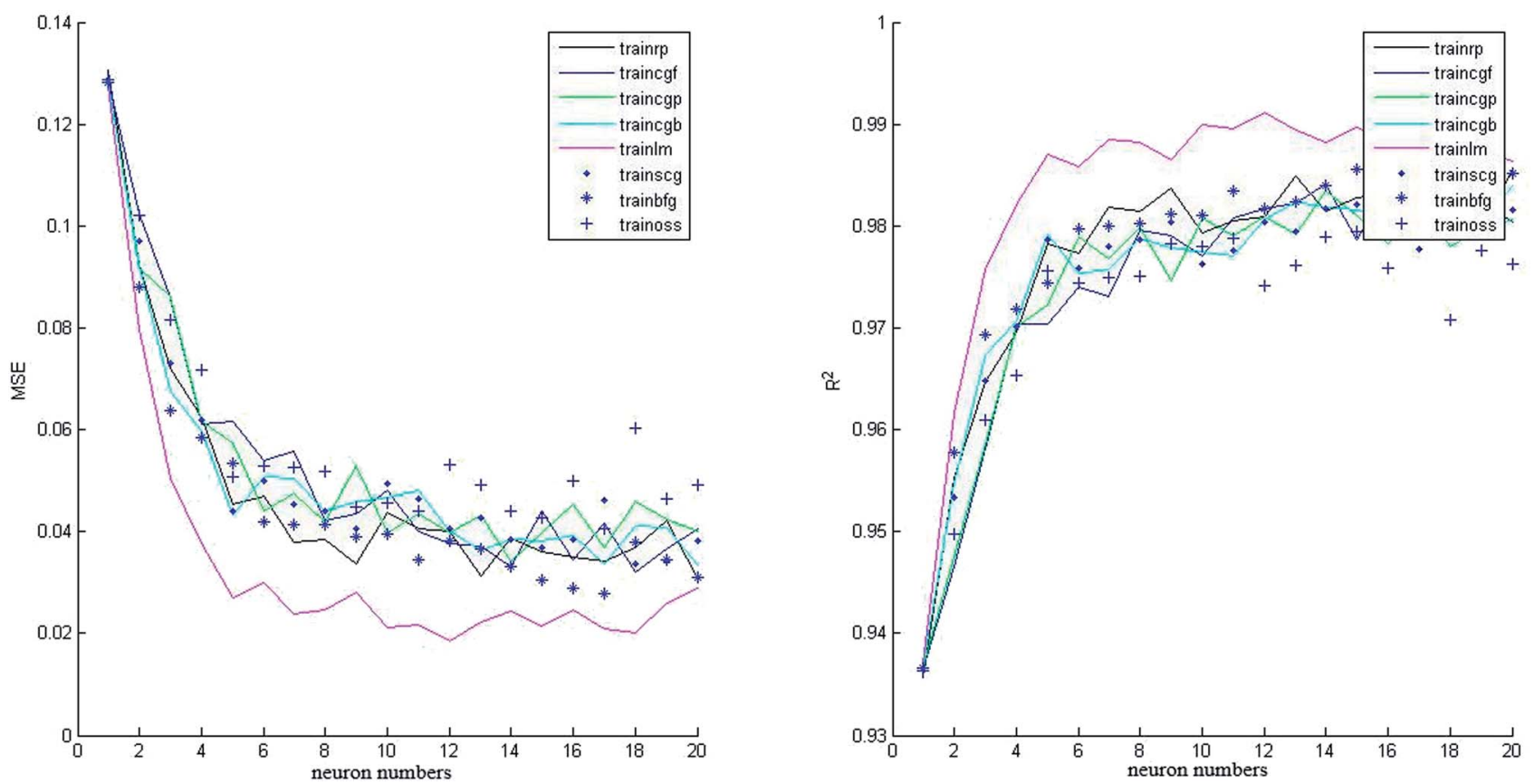

Fig. 4 Effect of the number of neurons on MSE and correlation coefficient $\left(R^{2}\right)$ values for various training algorithms (logsig function in the hidden layer).

was divided into three matrices: validation set $(20 \%)$, test set $(20 \%)$ and training set (60\%). All the data applied in this study are shown in Appendix A (Table A1). Two neural networks were constructed with different transfer functions in the hidden layer: tansig and logsig equations. Various neuron numbers and training functions were studied to find the best architecture of the intelligent network. As shown in Fig. 3 and 4, eight training algorithms with different network sizes (1 to 20 neurons) were compared to gain the best suitable back-propagation. Fig. 3 and 4 illustrate the measured minimum MSE (0.1881 and 0.2143), and correlation coefficient $\left(R^{2}=0.9221\right.$ and $\left.R^{2}=0.9826\right)$ values in the hidden layer versus the number of neurons for tansig and logsig activation functions, respectively. It can be concluded that tansig function in the hidden layer could be the best choice for modelling input variables according to the experimental data. Clearly, trainlm algorithm with the minimum MSE and the highest correlation coefficient was the best choice for updating the weights and biases of the two different networks, as reported in Table 2 . There was absolutely no change in MSE

Table 2 Performances of various training functions for the network with the tansig function ${ }^{a}$

\begin{tabular}{lcccl}
\hline Training functions & MSE & IN & $R^{2}$ & BLE \\
\hline Trainrp & 0.0400 & 85 & 0.980 & $Y=0.96 X+2.6$ \\
Traincgf & 0.0404 & 76 & 0.981 & $Y=0.98 X+1.3$ \\
Traincgp & 0.0390 & 47 & 0.981 & $Y=0.96 X+2.7$ \\
Traincgb & 0.0369 & 43 & 0.982 & $Y=0.97 X+1.9$ \\
Trainlm & 0.0178 & 28 & 0.992 & $Y=0.99 X+0.72$ \\
Trainscg & 0.0402 & 62 & 0.981 & $Y=0.97 X+2.5$ \\
Trainbfg & 0.0386 & 31 & 0.982 & $Y=0.98 X+0.61$ \\
Trainoss & 0.0384 & 81 & 0.981 & $Y=0.98 X+1.2$
\end{tabular}

${ }^{a} \mathrm{IN}=$ iteration number, BLE $=$ best linear equation. and correlation coefficient values with an increase in network size beyond 11 neurons. Approximately, as shown in Fig. 5, good performance was shown by neural networks with similar outputs between logsig and tansig functions in various training algorithms. The results also indicated that the network with the tansig function might be better than that with the logsig function in the hidden layer.

The comparison between collected experimental data and the predicted data is shown in Fig. 6 for tansig and logsig functions. It was clear that there was a good agreement between experimental and predicted data while using tansig as the transfer function.

The effect of each input variable was evaluated using sensitivity analysis by the combination of one, two, three, four, five and six variables in the optimal ANN constructed by tansig functions in a hidden layer with 11 neurons and trainlm as the training algorithm. In each row of Table 3, variables in the first column were varied, while the other variables were kept constant at their average values. As shown in Table 3, the oxidation temperature was the most effective variable among one-variable groups with the minimum value of MSE $=145.435$. The combination of (oxidation temperature + initial concentration of cyclohexane) among two-variable groups, the combination of (oxidation temperature + initial concentration of toluene + catalyst structure) in three-variable groups, the combination of (oxidation temperature + initial concentration of toluene + catalyst structure + cobalt content) in four-variable groups, and finally, the combination of (oxidation temperature + initial concentration of toluene + initial concentration of cyclohexane + catalyst structure + copper content) in fivevariable groups had the minimum values of MSE. Generally, it was clear from Table 3 that with the enhancement of the 

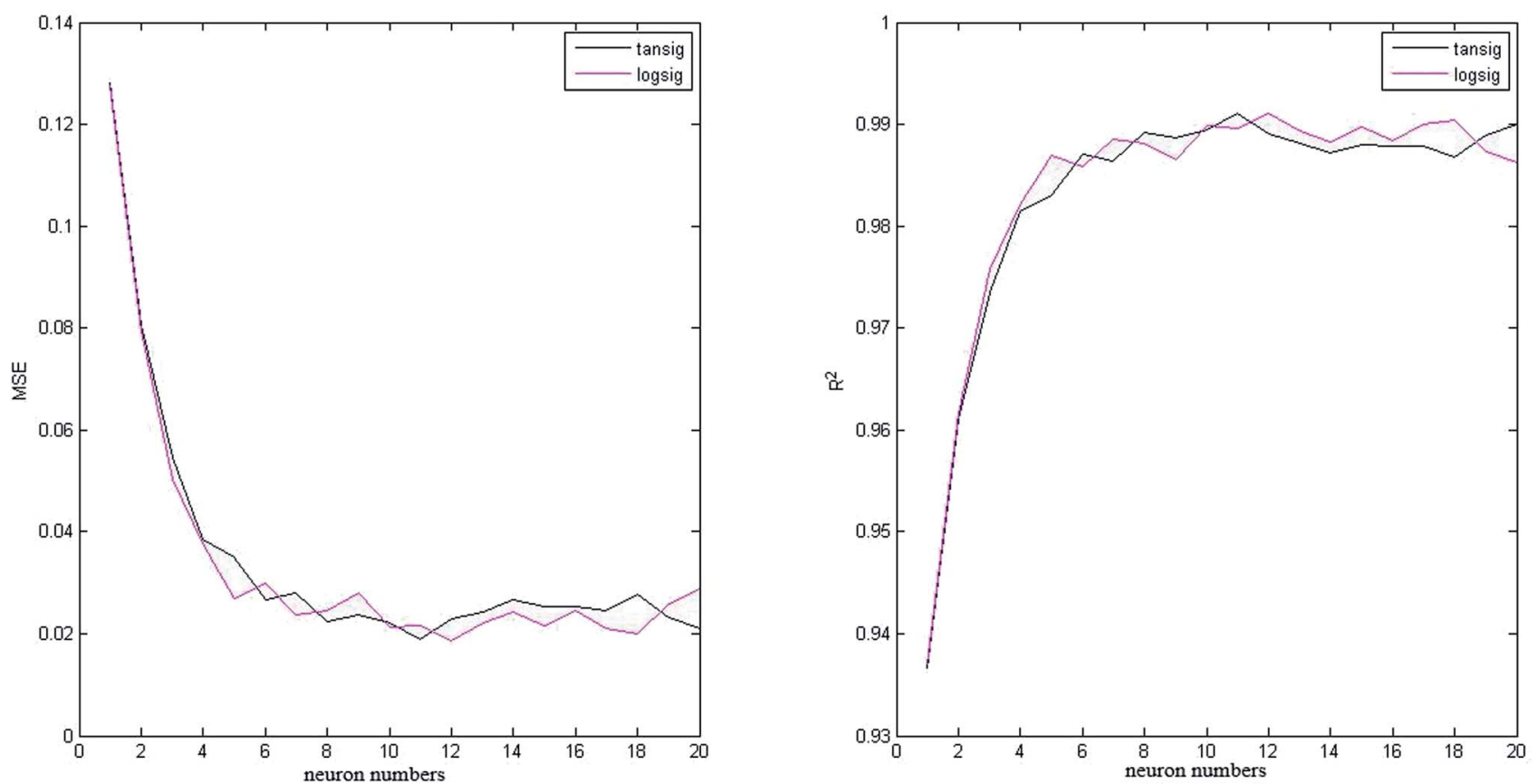

Fig. 5 Comparison between two different networks (tansig and logsig as transfer functions).

number of parameters, the value of MSE decreased. As shown in Table 3, in the two-variable group, the temperature of the reaction and the initial concentration of cyclohexane had a significant effect on the complete oxidation of toluene in air. Furthermore, the results showed that the effect of initial concentration of cyclohexane decreased with the variation of cobalt loading over activated carbon. However, among other factors, the structure of the catalyst played the key role in the oxidation of toluene and cyclohexane. Therefore, preparation variables are the most important parameters to determine the highest conversion of VOCs.

\subsection{Optimization}

Optimization was conducted to prepare the optimal bimetallic catalyst by the obtained ANN as a fitness function of the GA algorithm. The initial concentration of toluene and cyclohexane, and the oxidation temperature were kept constant at values of $2000 \mathrm{ppmv}, 2000 \mathrm{ppmv}$ and $250{ }^{\circ} \mathrm{C}$, respectively, during the determination of the optimal catalyst. Crossover probability and mutation value were usually large and small (0.01-0.1), respectively. Therefore, several crossover and mutation rates were investigated to increase the speed of the algorithm to find the optimum point. Eventually, the evolutionary hybrid algorithm was inclined to converge after the 100th generation. The best and mean fitness function was plotted in Fig. 7, which indicated the sharp approach of the fitness function value to reach the best score. The optimum catalyst was realized after the evaluation of ANN_GA algorithm to achieve the highest toluene and cyclohexane conversions in air. Supported alloy nano bimetallic catalyst with $2.5 \mathrm{wt} \%$ copper and $5.5 \mathrm{wt} \%$ cobalt (weight ratio, $\mathrm{Cu}: \mathrm{Co}=1: 2$ ) was prepared by the HDP method as an optimum sample to compare with the computational results.

\subsection{Characterizations and performance of the optimum sample}

XRD patterns can explain the type and the size of crystallites as the active sites over activated carbon. Peaks of cobalt oxide, copper oxide and copper-cobalt oxide complexes were detected by X'Pert-High-Score software version $1.0 \mathrm{~d}$ by PANalytical-BV Almelo, Netherlands. Wide peaks with very weak intensities of $\mathrm{CuO}(\mathrm{ICDD}=00-001-1117,2 \theta=35.74), \mathrm{CoO}(\mathrm{ICDD}=00-001-$ $1227,2 \theta=42.61$ and 61.79) and $\mathrm{CoO} \cdot \mathrm{CuO}(\mathrm{ICDD}=01-074-$ $1855,2 \theta=37.91$ ) over the amorphous phase were observed due to activated carbon, as shown in Fig. 8. Wide peaks represented the small size of crystallites that could show the effective dispersion of metal oxides over activated carbon. The size of the crystallites can be calculated by Scherrer eqn (4) given below:

$$
D=\frac{K \lambda}{\beta \cos \theta}
$$

where $D$ is the mean crystallite diameter (nm), $K$ is the dimensionless shape factor ( $K=0.9$ for spheres), $\lambda$ is the X-ray wavelength (X-ray tube: $\mathrm{Cu}, \lambda=0.154 \mathrm{~nm}$ ), $\beta$ is the line broadening at the half maximum intensity, and $\theta$ is the Bragg angle. Measured sizes demonstrated that the minimum size of the crystallites was less than $20 \mathrm{~nm}$.

TEM images were recorded to evaluate the dispersion and the crystallite size of the as-prepared sample to confirm XRD results. Morphological images of $\mathrm{Cu} 2.5-\mathrm{Co5} .5 / \mathrm{AC}$ indicated the well dispersed nano-size spherical crystallites supported on porous activated carbon (Fig. 9). Two color groups were detected from the TEM image, namely, black and gray, which represented metal oxides and activated carbon, respectively. Average particle size of the optimal sample derived from Fig. 9 was found to be $6 \mathrm{~nm}$ by Clemex software. Therefore, these results indicated that smaller crystallites were formed by the HDP 


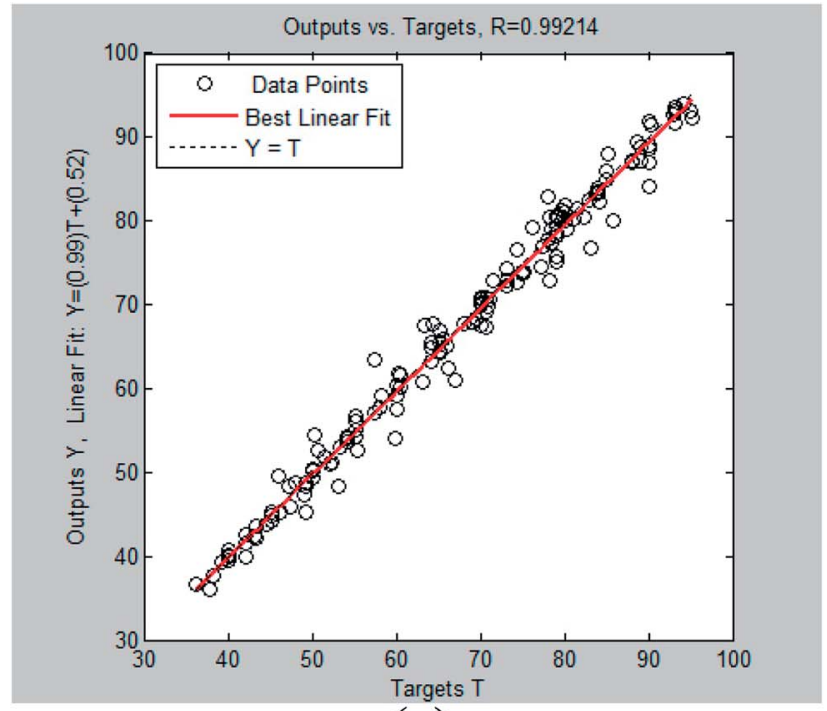

(a)

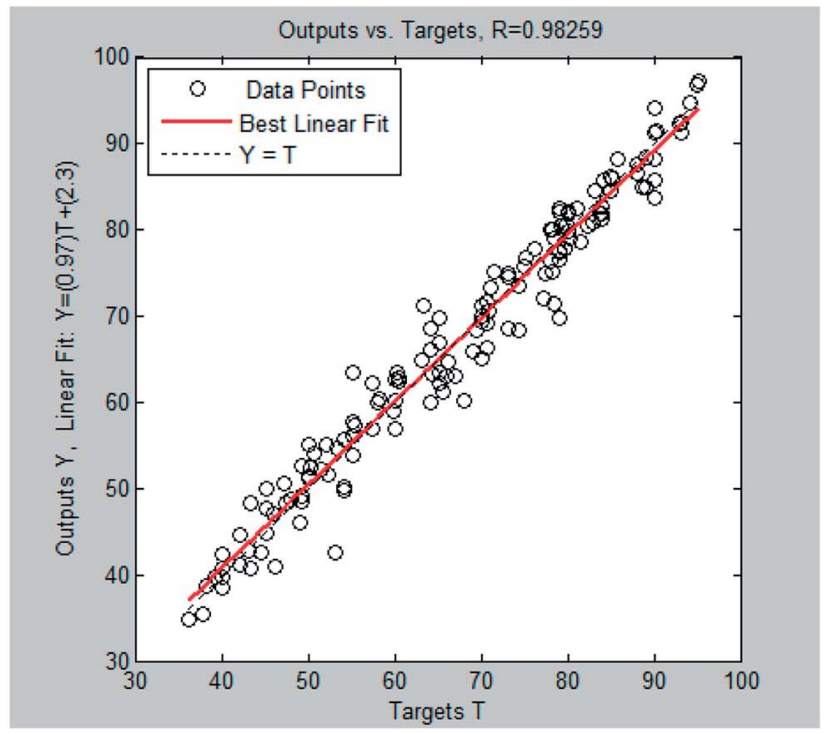

(b)

Fig. 6 (a) ANN output (predicted) plotted versus corresponding targets (tansig function in the hidden layer). (b) ANN output (predicted) plotted versus corresponding targets (logsig function in the hidden layer).

method using the obtained optimal synthesis conditions in comparison to prepared samples with the minimum measured diameter of $8 \mathrm{~nm}$ in our previously published paper. TEM image also illustrated spherical particles and crystallites, which was in good agreement with the shape factor obtained through the Scherrer equation.

ICP analysis was also carried out to determine the real metal oxide content on activated carbon. Small differences between nominal and ICP results reported in Fig. 9 showed that the HDP method was suitable to construct the best catalyst.

The FESEM micrographs of the as-prepared supported bimetallic catalyst after the optimization of synthesis
Table 3 Sensitivity analysis by the combination of input variables

\begin{tabular}{|c|c|c|c|c|}
\hline Combination & MSE & IN & $R^{2}$ & BLE \\
\hline A & 145.435 & 3 & 0.6478 & $Y=0.42 x+39$ \\
\hline B & 173.695 & 4 & 0.5572 & $Y=0.32 x+45$ \\
\hline $\mathrm{C}$ & 171.3323 & 4 & 0.5598 & $Y=0.31 x+46$ \\
\hline $\mathrm{D}$ & 219.7602 & 3 & 0.3714 & $Y=0.18 x+54$ \\
\hline $\mathrm{E}$ & 215.5642 & 4 & 0.3689 & $Y=0.13 x+59$ \\
\hline F & 200.3444 & 3 & 0.4532 & $Y=0.22 x+54$ \\
\hline$A+B$ & 76.3664 & 6 & 0.8343 & $Y=0.72 x+20$ \\
\hline$A+C$ & 95.6955 & 6 & 0.8136 & $Y=0.75 x+20$ \\
\hline$A+D$ & 143.1095 & 8 & 0.6648 & $Y=0.51 x+32$ \\
\hline$A+E$ & 130.0399 & 11 & 0.6931 & $Y=0.51 x+33$ \\
\hline$A+F$ & 107.5304 & 8 & 0.7561 & $Y=0.6 x+26$ \\
\hline $\mathrm{B}+\mathrm{C}$ & 171.8939 & 10 & 0.5611 & $Y=0.33 x+46$ \\
\hline$B+D$ & 165.9524 & 6 & 0.5910 & $Y=0.39 x+43$ \\
\hline$B+E$ & 176.6352 & 7 & 0.5420 & $Y=0.3 x+47$ \\
\hline $\mathrm{B}+\mathrm{F}$ & 132.8516 & 10 & 0.6863 & $Y=0.51 x+33$ \\
\hline$C+D$ & 161.2369 & 9 & 0.6022 & $Y=0.41 x+39$ \\
\hline $\mathrm{C}+\mathrm{E}$ & 160.7969 & 6 & 0.6009 & $Y=0.38 x+41$ \\
\hline $\mathrm{C}+\mathrm{F}$ & 155.4478 & 7 & 0.6418 & $Y=0.52 x+34$ \\
\hline$D+E$ & 217.3808 & 4 & 0.3720 & $Y=0.16 x+55$ \\
\hline$D+F$ & 179.7211 & 5 & 0.5311 & $Y=0.29 x+49$ \\
\hline$E+F$ & 175.4342 & 5 & 0.5461 & $Y=0.31 x+46$ \\
\hline$A+B+C$ & 76.5286 & 6 & 0.8333 & $Y=0.6 x+21$ \\
\hline$A+B+D$ & 56.5952 & 14 & 0.8842 & $Y=0.76 x+18$ \\
\hline$A+B+E$ & 54.9286 & 15 & 0.8841 & $Y=0.82 x+12$ \\
\hline$A+B+F$ & 42.1760 & 14 & 0.91223 & $Y=0.83 x+12$ \\
\hline$A+C+D$ & 57.6044 & 9 & 0.8777 & $Y=0.77 x+16$ \\
\hline$A+C+E$ & 57.7685 & 10 & 0.8801 & $Y=0.79 x+13$ \\
\hline$A+C+F$ & 34.73 & 20 & 0.9301 & $Y=0.87 x+9.8$ \\
\hline$A+E+F$ & 101.3071 & 9 & 0.7753 & $Y=0.61 x+28$ \\
\hline $\mathrm{B}+\mathrm{C}+\mathrm{D}$ & 150.1443 & 7 & 0.6336 & $Y=0.44 x+38$ \\
\hline$B+C+E$ & 151.2555 & 6 & 0.6326 & $Y=0.4 x+39$ \\
\hline $\mathrm{B}+\mathrm{C}+\mathrm{F}$ & 138.5619 & 7 & 0.6852 & $Y=0.54 x+33$ \\
\hline $\mathrm{B}+\mathrm{D}+\mathrm{E}$ & 150.9032 & 11 & 0.6315 & $Y=0.4 x+40$ \\
\hline$B+D+F$ & 120.3750 & 13 & 0.7321 & $Y=0.61 x+25$ \\
\hline $\mathrm{B}+\mathrm{E}+\mathrm{F}$ & 111.6485 & 16 & 0.7454 & $Y=0.56 x+29$ \\
\hline$C+D+E$ & 151.0813 & 14 & 0.6307 & $Y=0.43 x+39$ \\
\hline$C+D+F$ & 150.9258 & 9 & 0.7020 & $Y=0.56 x+34$ \\
\hline$C+E+F$ & 113.2508 & 9 & 0.7400 & $Y=0.56 x+31$ \\
\hline $\mathrm{D}+\mathrm{E}+\mathrm{F}$ & 184.9195 & 5 & 0.5401 & $Y=0.36 x+46$ \\
\hline$A+B+C+D$ & 59.9528 & 9 & 0.8724 & $Y=0.75 x+16$ \\
\hline$A+B+C+E$ & 58.0246 & 12 & 0.8770 & $Y=0.74 x+18$ \\
\hline$A+B+C+F$ & 36.9017 & 12 & 0.9234 & $Y=0.85 x+11$ \\
\hline$A+C+D+E$ & 56.7687 & 11 & 0.8811 & $Y=0.74 x+18$ \\
\hline$A+C+D+F$ & 9.907 & 20 & 0.98026 & $Y=0.96 x+3.3$ \\
\hline$A+D+E+F$ & 89.7582 & 10 & 0.8082 & $Y=0.6 x+27$ \\
\hline $\mathrm{B}+\mathrm{C}+\mathrm{D}+\mathrm{E}$ & 150.9517 & 9 & 0.6324 & $Y=0.42 x+38$ \\
\hline $\mathrm{B}+\mathrm{C}+\mathrm{D}+\mathrm{F}$ & 114.6047 & 14 & 0.7387 & $Y=0.6 x+28$ \\
\hline $\mathrm{B}+\mathrm{D}+\mathrm{E}+\mathrm{F}$ & 115.0186 & 12 & 0.7338 & $Y=0.53 x+31$ \\
\hline$C+D+E+F$ & 116.5159 & 9 & 0.7333 & $Y=0.57 x+28$ \\
\hline$A+B+C+D+E$ & 59.5521 & 10 & 0.8731 & $Y=0.79 x+14$ \\
\hline$A+B+C+D+F$ & 6.873 & 14 & 0.98633 & $Y=0.97 x+2.3$ \\
\hline$A+C+D+E+F$ & 9.7121 & 14 & 0.98057 & $Y=0.98 x+1.1$ \\
\hline$B+C+D+E+F$ & 13 & 13 & 0.7420 & $Y=0.57 x+29$ \\
\hline$A+B+D+E+F$ & 0.31 & 17 & 0.9861 & $Y=0.98 x+1.3$ \\
\hline$A+B+C+E+F$ & 0.23 & 16 & 0.988 & $Y=0.99 x+0.23$ \\
\hline $\mathrm{A}+\mathrm{B}+\mathrm{C}+\mathrm{D}+\mathrm{E}+\mathrm{F}$ & 0.01881 & 18 & 0.92214 & $Y=0.99 x+0.52$ \\
\hline
\end{tabular}

conditions show the surface morphologies, size distribution and dispersion of the particles (Fig. 10). It is observed that well dispersed bi-metal oxides were formed over the porous support with spherical shape. The alloy morphology with nanoparticles can be seen from micrographs, which confirmed the success of the preparation method, and XRD and TEM observations. 

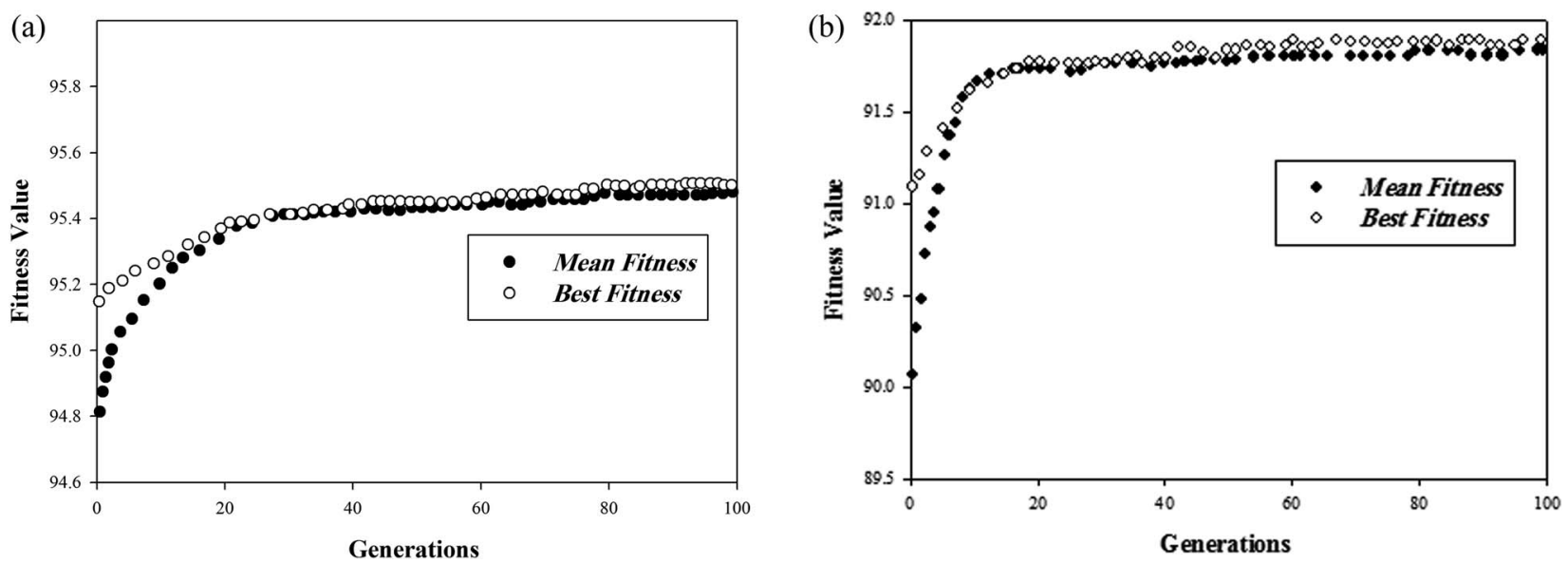

Fig. 7 (a) Maximum and average fitness function of toluene conversion over the optimal catalyst. (b) Maximum and average fitness function of cyclohexane conversion over the optimal catalyst.

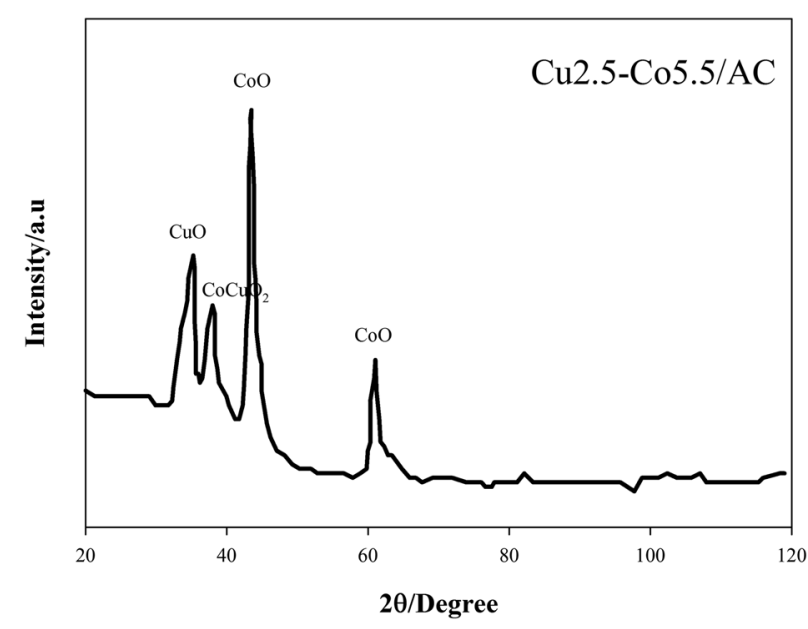

Fig. 8 XRD results of Cu2.5-Co5.5/AC as an optimal catalyst.
Determining the surface area of the catalyst can be used as an acceptable method to find the dispersion of metal oxides over the porous support. Surface area and the pore volume of the prepared catalyst were measured to be about $76 \mathrm{~m}^{2} \mathrm{~g}^{-1}$ and $18.60 \mathrm{~cm}^{3} \mathrm{~g}^{-1}$ by BET and BJH theory, respectively. Surface area of almond shell-activated carbon (support) was $860 \mathrm{~m}^{2} \mathrm{~g}^{-1} \cdot{ }^{9}$ Therefore, the surface area decreased with the increase in the metal content over activated carbon due to blocking of the pores, indicating high dispersion of metal oxide crystallites over the porous support.

The optimum catalyst based on the results of the hybrid optimization algorithm demonstrated higher performances than those of the prepared samples in our previous study. This investigation and modeling could confirm that toluene and cyclohexane conversion enhanced with the increase in cobalt

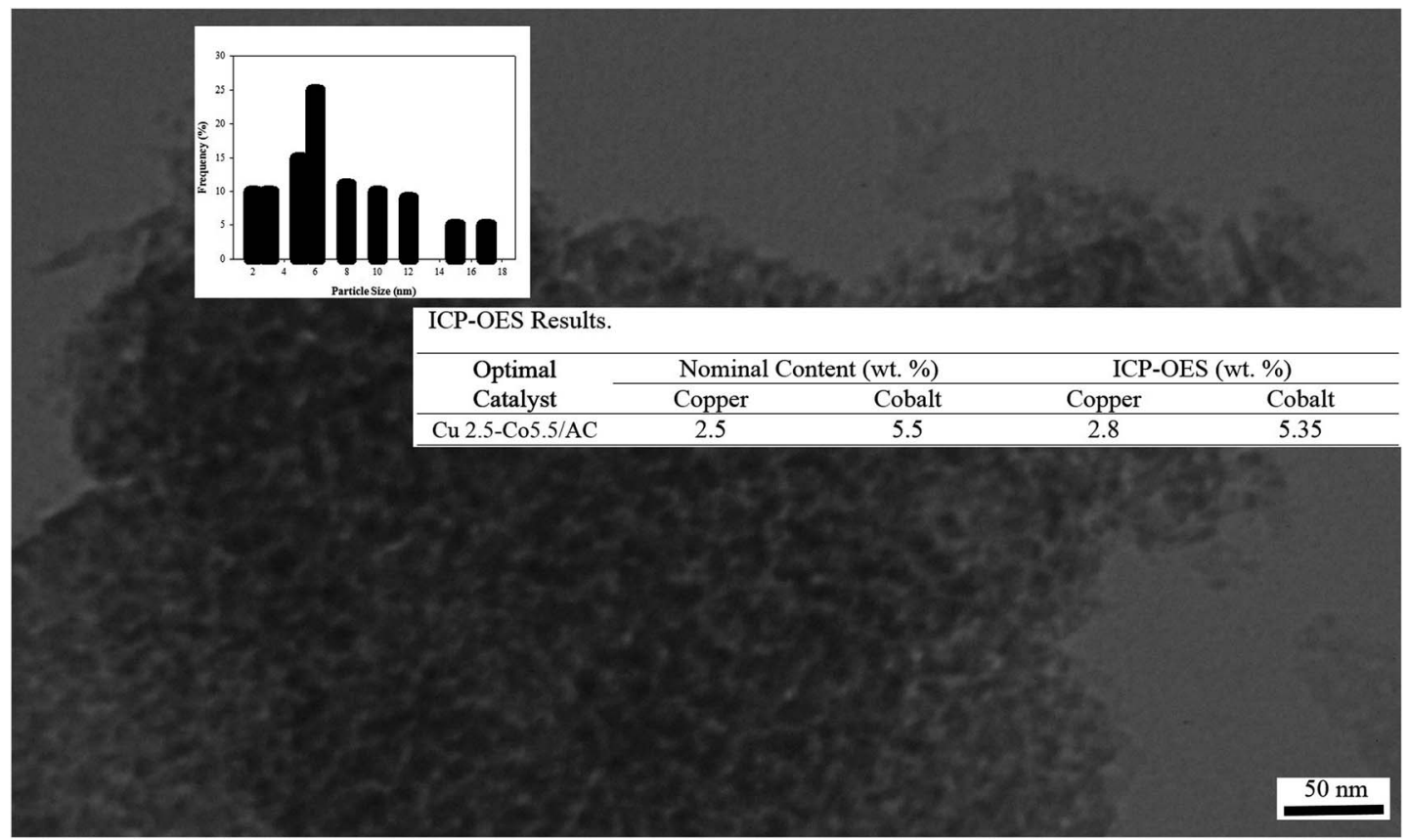

Fig. 9 TEM and ICP results of Cu2.5-Co5.5/AC as an optimal catalyst. 


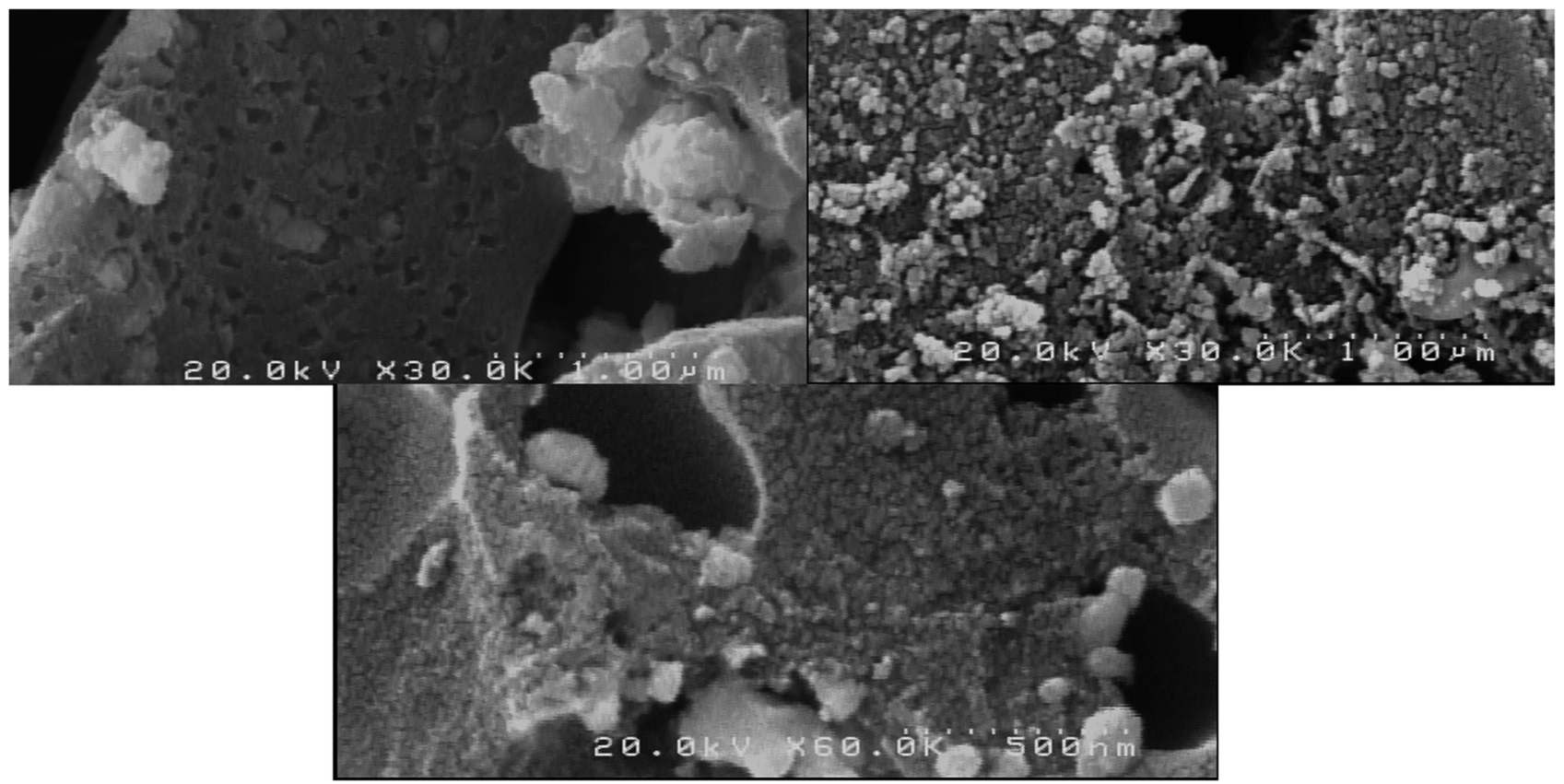

Fig. 10 FESEM results of Cu2.5-Co5.5/AC as an optimal catalyst.

content over almond shell-activated carbon, which has been reported in previous studies.

Investigation of catalytic activity was carried out for about 60 hours with Cu2.5-Co5.5/AC under constant operating conditions of reaction temperature of $250{ }^{\circ} \mathrm{C}$ and initial concentration of cyclohexane and toluene at $1000 \mathrm{ppmv}$ in the bicomponent feed. Fig. 11 illustrates the high activity and stability of the optimal bimetallic catalyst in comparison to the prepared samples in our previously published report ${ }^{9}$ for the complete conversion of toluene and cyclohexane in air. The experimental study also showed that there were no significant differences between the obtained conversion values for VOCs from modeling (toluene conversion $=95.5 \%$ and cyclohexane

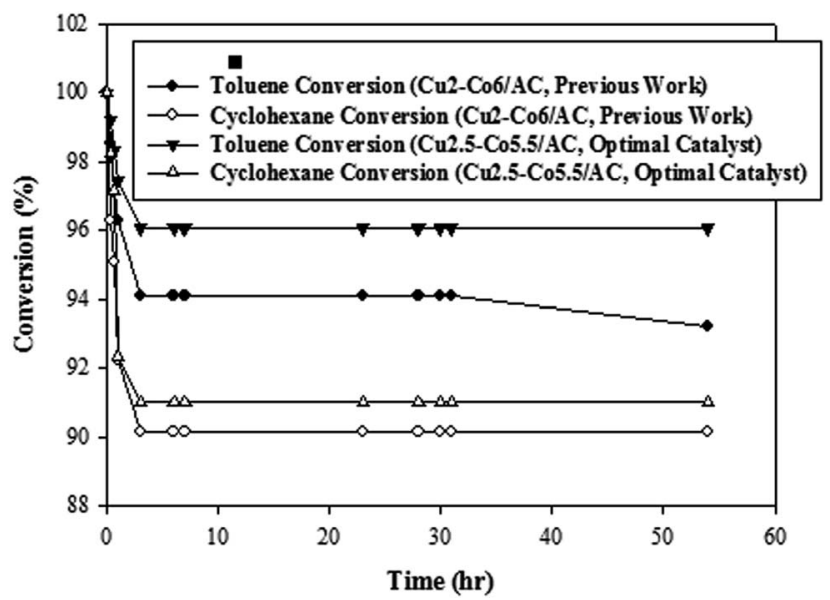

Fig. 11 Long performance of Cu2.5-Co5.5/AC (optimal catalyst) and Cu2-Co6/AC (pervious work) for simultaneous conversion of toluene and cyclohexane in air (initial concentration $=1000$ ppmv and oxidation temperature $=250^{\circ} \mathrm{C}$ ). conversion $=91.88 \%$ ) and from the results of the micro-reactor (toluene conversion $=96 \%$ and cyclohexane conversion $=$ 91\%). Therefore, based on the validation, synthesis and operating results, we can rely on the ability and the accuracy of the hybrid model.

\section{Conclusions}

A hybrid algorithm using genetic and neural networks was applied to generate a non-linear model to predict and measure the operating condition parameters and the optimal catalyst for the total oxidation of toluene and cyclohexane. Catalytic oxidation evaluated by the model was in good agreement with the experimental data. The maximum correlation coefficient of 0.9921 between calculated and experimental results was measured from the artificial neural network with 11 neurons and tansig as a transfer function of the hidden layer. Based on the sensitivity analysis, the oxidation temperature and the initial concentration of cyclohexane are the most effective parameters for the complete oxidation of toluene and cyclohexane. The highest conversions of toluene and cyclohexane were $96 \%$ and $91 \%$ by employing the optimal catalyst at respective constant operating conditions (reaction temperature $=250^{\circ} \mathrm{C}$ and initial concentration of VOCs $=1000 \mathrm{ppmv}$ ). The realized catalyst consists of $2.5 \mathrm{wt} \%$ copper oxide and $5.5 \mathrm{wt} \%$ cobalt oxide dispersed over almond shell-based activated carbon by the co-HDP preparation method (alloy catalyst). CoO, $\mathrm{CuO}$ and $\mathrm{CuCoO}_{2}$ were formed over the porous support as nanosized crystallites (below $10 \mathrm{~nm}$ ) according to the XRD results. A well dispersed supported nano-catalyst was indicated by TEM and FESEM images, while the success of the preparation method was confirmed by ICP-OES analysis. 


\section{Appendix A}

Table A1 Selected data from our previous study for use in the hybrid intelligent algorithm ${ }^{9}$

\begin{tabular}{|c|c|c|c|c|c|c|}
\hline $\begin{array}{l}\text { Oxidation } \\
\text { temperature }\left({ }^{\circ} \mathrm{C}\right)\end{array}$ & $\begin{array}{l}\text { Initial concentration of } \\
\text { toluene and } \\
\text { cyclohexane (ppmv) }\end{array}$ & $\begin{array}{l}\text { Cobalt content } \\
\text { (wt } \%)\end{array}$ & $\begin{array}{l}\text { Copper content } \\
\text { (wt\%) }\end{array}$ & $\begin{array}{l}\text { Structure of } \\
\text { catalyst }^{a}\end{array}$ & $\begin{array}{l}\text { Toluene } \\
\text { conversion (\%) }\end{array}$ & $\begin{array}{l}\text { Cyclohexane } \\
\text { conversion (\%) }\end{array}$ \\
\hline 250 & 1000 & 2 & 6 & 1 & 81.1 & 77.4 \\
\hline 250 & 2000 & 2 & 6 & 1 & 78.37 & 70.01 \\
\hline 250 & 4000 & 2 & 6 & 1 & 60.17 & 57.3 \\
\hline 250 & 8000 & 2 & 6 & 1 & 48 & 55.1 \\
\hline 250 & 1000 & 4 & 4 & 1 & 89.14 & 81.4 \\
\hline 250 & 2000 & 4 & 4 & 1 & 85.11 & 78.2 \\
\hline 250 & 4000 & 4 & 4 & 1 & 77.1 & 60.3 \\
\hline 250 & 8000 & 4 & 4 & 1 & 60 & 58.2 \\
\hline 250 & 1000 & 6 & 2 & 1 & 94.11 & 90.14 \\
\hline 250 & 2000 & 6 & 2 & 1 & 93.18 & 82.2 \\
\hline 250 & 4000 & 6 & 2 & 1 & 79 & 70.81 \\
\hline 250 & 8000 & 6 & 2 & 1 & 65 & 66.1 \\
\hline 250 & 1000 & 2 & 6 & 2 & 79 & 79 \\
\hline 250 & 2000 & 2 & 6 & 2 & 73 & 70 \\
\hline 250 & 4000 & 2 & 6 & 2 & 50 & 50 \\
\hline 250 & 8000 & 2 & 6 & 2 & 40 & 40 \\
\hline 250 & 1000 & 4 & 4 & 2 & 85 & 79.9 \\
\hline 250 & 2000 & 4 & 4 & 2 & 78 & 71.14 \\
\hline 250 & 4000 & 4 & 4 & 2 & 55 & 55 \\
\hline 250 & 8000 & 4 & 4 & 2 & 45 & 45 \\
\hline 250 & 1000 & 6 & 2 & 2 & 93.1 & 88.6 \\
\hline 250 & 2000 & 6 & 2 & 2 & 90.12 & 76.21 \\
\hline 250 & 4000 & 6 & 2 & 2 & 79 & 67.9 \\
\hline 250 & 8000 & 6 & 2 & 2 & 67 & 59.7 \\
\hline 250 & 1000 & 2 & 6 & 3 & 79 & 66 \\
\hline 250 & 2000 & 2 & 6 & 3 & 69 & 50.47 \\
\hline 250 & 4000 & 2 & 6 & 3 & 50 & 44.4 \\
\hline 250 & 8000 & 2 & 6 & 3 & 40 & 36 \\
\hline 250 & 1000 & 4 & 4 & 3 & 79.54 & 64 \\
\hline 250 & 2000 & 4 & 4 & 3 & 70.7 & 55.21 \\
\hline 250 & 4000 & 4 & 4 & 3 & 55 & 49 \\
\hline 250 & 8000 & 4 & 4 & 3 & 45 & 38 \\
\hline 250 & 1000 & 6 & 2 & 3 & 89 & 74.23 \\
\hline 250 & 2000 & 6 & 2 & 3 & 75 & 58 \\
\hline 250 & 4000 & 6 & 2 & 3 & 64.24 & 54 \\
\hline 250 & 8000 & 6 & 2 & 3 & 53.27 & 42 \\
\hline 150 & 2000 & 2 & 6 & 1 & 49.15 & 47.26 \\
\hline 200 & 2000 & 2 & 6 & 1 & 69.32 & 57.31 \\
\hline 250 & 2000 & 2 & 6 & 1 & 78.37 & 63.36 \\
\hline 300 & 2000 & 2 & 6 & 1 & 83.84 & 78 \\
\hline 350 & 2000 & 2 & 6 & 1 & 84 & 78.29 \\
\hline 150 & 2000 & 4 & 4 & 1 & 51.35 & 54.1 \\
\hline 200 & 2000 & 4 & 4 & 1 & 74.41 & 63.01 \\
\hline 250 & 2000 & 4 & 4 & 1 & 85.11 & 71.54 \\
\hline 300 & 2000 & 4 & 4 & 1 & 90 & 84 \\
\hline 350 & 2000 & 4 & 4 & 1 & 90.21 & 84.17 \\
\hline 150 & 2000 & 6 & 2 & 1 & 60 & 52.21 \\
\hline 200 & 2000 & 6 & 2 & 1 & 83.75 & 64 \\
\hline 250 & 2000 & 6 & 2 & 1 & 93.18 & 79.2 \\
\hline 300 & 2000 & 6 & 2 & 1 & 95 & 90 \\
\hline 350 & 2000 & 6 & 2 & 1 & 95.17 & 90.1 \\
\hline 150 & 2000 & 2 & 6 & 2 & 46 & 43 \\
\hline 200 & 2000 & 2 & 6 & 2 & 64 & 60 \\
\hline 250 & 2000 & 2 & 6 & 2 & 73 & 70 \\
\hline 300 & 2000 & 2 & 6 & 2 & 80 & 79 \\
\hline
\end{tabular}


Table A1 (Contd.)

\begin{tabular}{|c|c|c|c|c|c|c|}
\hline $\begin{array}{l}\text { Oxidation } \\
\text { temperature }\left({ }^{\circ} \mathrm{C}\right)\end{array}$ & $\begin{array}{l}\text { Initial concentration of } \\
\text { toluene and } \\
\text { cyclohexane (ppmv) }\end{array}$ & $\begin{array}{l}\text { Cobalt content } \\
\text { (wt\%) }\end{array}$ & $\begin{array}{l}\text { Copper content } \\
\text { (wt \%) }\end{array}$ & $\begin{array}{l}\text { Structure of } \\
\text { catalyst }^{a}\end{array}$ & $\begin{array}{l}\text { Toluene } \\
\text { conversion (\%) }\end{array}$ & $\begin{array}{l}\text { Cyclohexane } \\
\text { conversion (\%) }\end{array}$ \\
\hline 350 & 2000 & 2 & 6 & 2 & 80.31 & 79.11 \\
\hline 150 & 2000 & 4 & 4 & 2 & 53 & 45.89 \\
\hline 200 & 2000 & 4 & 4 & 2 & 65 & 65.42 \\
\hline 250 & 2000 & 4 & 4 & 2 & 78 & 71.14 \\
\hline 300 & 2000 & 4 & 4 & 2 & 88 & 83 \\
\hline 350 & 2000 & 4 & 4 & 2 & 88 & 83.11 \\
\hline 150 & 2000 & 6 & 2 & 2 & 50.12 & 49.1 \\
\hline 200 & 2000 & 6 & 2 & 2 & 78.37 & 70.59 \\
\hline 250 & 2000 & 6 & 2 & 2 & 90.12 & 76.21 \\
\hline 300 & 2000 & 6 & 2 & 2 & 93 & 85 \\
\hline 350 & 2000 & 6 & 2 & 2 & 93.11 & 85.74 \\
\hline 150 & 2000 & 2 & 6 & 3 & 42 & 37.6 \\
\hline 200 & 2000 & 2 & 6 & 3 & 52 & 42 \\
\hline 250 & 2000 & 2 & 6 & 3 & 69 & 50.47 \\
\hline 300 & 2000 & 2 & 6 & 3 & 70 & 65 \\
\hline 350 & 2000 & 2 & 6 & 3 & 70.7 & 65 \\
\hline 150 & 2000 & 4 & 4 & 3 & 43.1 & 39.11 \\
\hline 200 & 2000 & 4 & 4 & 3 & 54 & 43.12 \\
\hline 250 & 2000 & 4 & 4 & 3 & 70.7 & 55.21 \\
\hline 300 & 2000 & 4 & 4 & 3 & 75 & 70 \\
\hline 350 & 2000 & 4 & 4 & 3 & 75.1 & 70 \\
\hline 150 & 2000 & 6 & 2 & 3 & 49.17 & 40 \\
\hline 200 & 2000 & 6 & 2 & 3 & 60.4 & 47 \\
\hline 250 & 2000 & $\mathrm{a}$ & 2 & 3 & 75 & 58 \\
\hline 300 & 2000 & 6 & 2 & 3 & 80 & 73 \\
\hline 350 & 2000 & 6 & 2 & 3 & 80 & 73 \\
\hline
\end{tabular}

\section{Conflicts of interest}

There are no conflicts to declare.

\section{References}

1 Z. Sihaib, F. Puleo, J. M. Garcia-Vargas, L. Retailleau, C. Descorme, L. F. Liotta, J. L. Valverde, S. Gil and A. Giroir-Fendler, Appl. Catal., B, 2017, 209, 689-700.

2 J. Du, Z. Qu, C. Dong, L. Song, Y. Qin and N. Huang, Appl. Surf. Sci., 2018, 433, 1025-1035.

3 M. Zabihi, J. Shayegan, M. Fahimirad and F. Khorasheh, J. Porous Mater., 2015, 22, 101-118.

4 M. Zabihi, F. Khorasheh and J. Shayegan, React. Kinet., Mech. Catal., 2015, 114, 611-628.

5 Z. Ruia, M. Tangb, W. Jia, J. Dingb and H. Ji, Catal. Today, 2017, 297, 159-166.

6 M. Esmaeilirad, M. Zabihi, J. Shayegan and F. Khorasheh, J. Hazard. Mater., 2017, 333, 293-307.

7 L. A. Calzada, S. Collins, C. W. Han, V. Ortalan and R. Zanella, Appl. Catal., B, 2017, 207, 79-92.

8 A. Sandoval, A. Aguilar, C. Louis, A. Traverse and R. Zanella, J. Catal., 2011, 281, 40-49.

9 M. Zabihi, F. Khorasheh and J. Shayegan, RSC Adv., 2015, 5, 5107-5122.
10 S. A. Hosseini, A. Niaei, D. Salari and S. R. Nabavi, J. Taiwan Inst. Chem. Eng., 2014, 45, 85-91.

11 M. Steijins, F. Derks, A. Verloop and P. Mars, J. Catal., 1976, 42, 87-95.

12 S. Bahrami, A. Niaei, M. J. Illán-Gómez, A. Tarjomannejad and S. M. Mousavi, J. Environ. Chem. Eng., 2017, 5, 4937-4947.

13 M. ErdemGünaya and R. Yildirim, Appl. Catal., A, 2013, 468, 395-402.

14 U. Maity, J. Kumar Basu and S. Sengupta, Fuel, 2013, 113, 180-186.

15 J. H. Hartman, S. D. Cothren, S.-H. Park, C. H. Yun, J. A. Darsey and G. P. Miller, Bioorg. Med. Chem., 2013, 21, 3749-3759.

16 S. Sunphorka, B. Chalermsinsuwan and P. Piumsomboon, J. Energy Inst., 2015, 1-11.

17 F. Qian, L. Tao, W. Sun and W. Du, Ind. Eng. Chem. Res., 2012, 51, 3229-3237.

18 S. Sadighi, R. Seif-Mohaddecy and A. Norouzian, Bull. Chem. React. Eng. Catal., 2015, 10(2), 210-220.

19 P. R. Zonouz, A. Niaei and A. Tarjomannejad, J. Taiwan Inst. Chem. Eng., 2016, 1-10.

20 B. Izadkhah, S. R. Nabavi, A. Niaei, D. Salari, T. MahmuodiBadiki and N. Çaylak, J. Taiwan Inst. Chem. Eng., 2012, 18, 2083-2091.

21 S. A. Oskoui, A. Niaei, H. Hsin Tseng, D. Salari, B. Izadkhah and S. A. Hosseini, ACS Comb. Sci., 2013, 15, 609-621. 